\title{
The Relationship between Undergraduate Students' Parenting Style and Creativity
}

\author{
Yuchen Fang1, Yuhan Shen ${ }^{2}$ \\ ${ }^{1}$ Zhejiang Gongshang University, Hangzhou, China \\ ${ }^{2}$ Hangzhou No.4 High School, Hangzhou, China \\ Email: 1814807460@qq.com, 1366039474@qq.com
}

How to cite this paper: Fang, Y. C., \& Shen, Y. H. (2021). The Relationship between Undergraduate Students' Parenting Style and Creativity. Psychology, 12, 498-510. https://doi.org/10.4236/psych.2021.124031

Received: January 29, 2021

Accepted: April 9, 2021

Published: April 12, 2021

Copyright $\odot 2021$ by author(s) and Scientific Research Publishing Inc. This work is licensed under the Creative Commons Attribution International License (CC BY 4.0).

http://creativecommons.org/licenses/by/4.0/ (c) (i) Open Access

\begin{abstract}
Purpose: Taking into account previous research on the role that the parenting styles to which individuals are exposed during childhood have in shaping prosocial behaviors, attitudes and personality and so on, this study aims to investigate the relationship between parenting styles of parents and creativity. Design/Methodology/Approach: The creativity and the parenting style questionnaires were completed by 239 undergraduate student participants. Pearson correlation coefficients were extracted and regression analysis was performed. Findings: The results indicate that undergraduate students with democratic parents tend to show stronger creative thinking and open the way to further study what parental characteristics may be responsible for the development of creativity in undergraduate students. Research Limitations/Implications: Participants retrospectively assessed their parents' style. Future research may recruit both the actual parents of participants to collect more accurate data on parenting practices or use observational methods. Social Implications: This work seems to suggest that to achieve a more creative society, the ability of parents to raise their children by adopting a democratic style should be taken into account and-if needed-enhanced. Originality/Value: To the best of authors' knowledge, this is the first study to investigate the relationship between parenting styles of parents and creativity.
\end{abstract}

\section{Keywords}

Parenting Style, Democratic Parenting Style, Creativity

\section{Introduction}

Innovation is the soul of a nation's progress, the inexhaustible source of a country's prosperity and the deepest national endowment. Young people, especially 
undergraduate students are the most dynamic and creative group in society, and they should take the lead in innovation and creation. Young people must have the courage to innovate and create. Among researchers, there appears to be reasonable consensus regarding the definitional elements of creativity. Most researchers agreed that the two elements that define creativity are novelty and usefulness (Shalley, 1991). According to Gurteen (1998), innovation is the taking of new or existing ideas and turning them into action. Creativity, known as the engine of scientific discovery, is usually defined as the ability to produce novel, unique and valuable products under specific circumstances. Undergraduate students are a core component of China's working future, and improving their creative abilities to meet the demands of the technological age is very critical. Administrators and educators at Chinese universities should try to inspire students to express their ideas and creativity (Baker \& Baker, 2012). To prepare undergraduate students for the demands of the technological age, undergraduate students would have opportunities to improve both their convergent and divergent modes of thinking, as high-level creative thinking is essential when preparing undergraduate students for the demands that they will encounter in the future (Guilford, 1950). Most undergraduate students develop rapidly in body and mind, are active in thinking, have strong thirst for knowledge, and have the ability to think independently, find and solve problems. Undergraduates are the product of universities, and once they graduate, they become the source of manpower for developing the nation's economy. However, some college students do not have creative thinking, and find it is difficult to solve the actual new problems in the work. To some extent, it has hindered the development of the labour market. Academics and educators should focus on the creativity of undergraduates before they enter the company, which is often considered the "end user" of the labor market graduate supply chain.

Creativity is not as vague as some people think, and even those who do not think of themselves as creative can be educated and applied in everyday innovation (Tanner, 1992). School education is generally regarded as the main channel for cultivating students' creativity. Universities are increasingly expected to implement creative problem-solving in their educational curricula to meet the capacity needs of a profoundly changing society. Therefore, educators are working hard to develop effective teaching methods to stimulate and cultivate students' creativity (Bourgeois-Bougrine et al., 2017; Lin \& Nabergoj, 2014). Entrepreneurship education programme, or incorporating creativity cultivation into interdisciplinary collaborative teaching also provides a reference for setting up the carrier of creativity cultivation. However, it is not clear whether education has the power and influence to induce such intrinsic motivation and enjoyment in students, or to change their creativity in this way. This creative tendency in an individual's personality may take more time to develop. But it's possible that creativity isn't innate and you have to grow with it, so childhood experiences have to have an impact on creativity. To be precise, parental education is the 
source of creativity, and the family is the fertile ground for creativity. Because child discipline is the foundation and prophase of schooling, the development of creativity cannot begin after a child has gone to college. There is no doubt that the key to childhood experiences is highly related with parenting styles.

Parenting's distinct socialization orientations have been defined as parental styles (Baumrind, 1968). The terms of characterizing the styles have varied these years. For example, parental "warmth" versus "hostility" has also been termed "overprotective" versus "authoritarian" (Carlson et al., 1992) and "warmth" has also been called "nurturance" (Carlson et al., 2001). More recent parental style typology identified four categories depending on parents' levels of nurturing and authoritarianism (Neeley \& Coffey, 2007). The four parental styles are: authoritative (high nurturing/high authoritarian), authoritarian (low nurturing/high authoritarian), permissive (high nurturing/low authoritarian) and neglecting (low nurturing/low authoritarian).

Authoritarian parents have a lot of strict rules and very high standards. Many of these rules are designed to control a child's behavior or activities. Children should follow these rules from an early age. Children do not have much free space. Authoritarian parents are rarely warm to their children but are cold, unkind, and harsh. They use "tough love" to justify their cold and mean attitude towards their children. Authoritarian parents suppress their love for their children when they do not meet their expectations. Authoritarian parents think of themselves as authority figures, and their children should no doubt blindly obey that authority. Logically, the more control parents have over their children, the more likely they are to be timid and uncreative. However, the development of creativity needs a relaxed environment, children can imagine, and sometimes even destroy. If parents are too authoritarian, it can be detrimental to a child's creativity. It is logical too much parental control may lead to timidity and lack of creativity.

Providing autonomy support-i.e. the tendency to encourage children toward exploration and the development of their own views of the world-promotes the internalization of rules (Barber, 1996). These facets of parenting style seem to be modestly related to the Five Factor Model of personality's profiles. The association was investigated in a meta-analytic review showing that all five traits seemed to be related to warmth and behavioral control whereas autonomy support was related to agreeableness and neuroticism (Prinzie et al., 2009). Obviously, encouraging children toward exploration and the development of their own views of the world is conducive to the development of children's creativity. Research shows that such style plays an important role in promoting healthy and pro-social development (Baumrind, 1991; Buri, 1991; Barber et al., 2005; Barber \& Olsen, 1997; Gafor, 2014).

Bowlby has pointed out that the upbringing, attitude and interaction between parents and children in the early years have a great influence on the development of individual personality, and characteristics of personality are the main factors that influence the individual's dealing with affairs and coping with prac- 
tical problems in the future (1977). Other studies have shown that parenting styles can be divided into two main interpersonal, interactive levels, namely care and protection.

According to previous research, parenting styles individuals are exposed to during childhood have long lasting effects on individual's personality. Such as Davis \& Carlo (2018) found parents' practice, social rewards were positively associated with perspective taking, empathic concern, and prosocial moral reasoning, which were each associated with multiple forms of prosocial behaviors, explaining the links between parenting practices and low-income adolescents' prosocial behaviors. Other previous research also investigated the relationship between parenting styles and personality. Prinzie et al. (2009) showed all five traits seemed to be related to warmth and behavioral control whereas autonomy support was related to agreeableness and neuroticism. According to Big Five theory, openness to experience describes a person's cognitive style, his or her interest and enthusiasm in novelty. Highly open-minded people are imaginative, creative, curious, artistically sensitive and have a wide range of interests. The openness to experience is related to the creativity.

Authoritative behavior involves setting clear boundaries appropriate for the child's age and development, which the children are expected to follow Child Development; The parents show caring behavior when disciplining, taking time to explain why their children are being disciplined, but also listening to their needs and concerns. Previous research showed that authoritative parenting could lead to a host of positive effects in terms of emotion regulation and relational skills (Eisenberg, Cumberland, \& Spinrad, 1998; Eisenberg, Spinrad, \& Cumberland, 1998; Strayer \& Roberts, 2004; Bugental \& Grusec, 2006; Morris et al., 2007). According to the British newspaper The Guardian, this parenting behavior gives children a wide range of benefits, including having more success at school, positive social skills and a better understanding of other people. Therefore, it is reasonable to hypothesize that such styles may hold a relationship with creativity. Creative children may be very inquisitive and ask all sorts of odd questions, and how their parents treat them will have a different impact on their creative battles. For example, if the caregiver discouraged him or encouraged him, the outcome would be different. More specifically, we guess that individuals who rated their parents higher in democratic parenting style will show higher creativity scores and higher in authoritarian or neglecting parenting style will show lower creativity scores.

Gong YiHua (2006) developed the Parenting Styles Questionnaire on undergraduate students' which consisted of 40 items and 4 secondary scales including authoritarian, democratic, indulgence and neglecting styles. The reliability coefficients of 4 secondary scales were between $0.61-0.86$, and the reliability and validity of the scale were suitable. According to Gong YiHua (2006), Democratic parenting is characterized by a demand and response to the child, a focus on the child's physical and mental development, supervision of the child, but not too 
restrictive, guidance and assistance, a proper response to the child's demands, and trust in the child, respect the wishes of the child, communicate equally between parents and children, listen to and absorb the views of the child, encourage the child self-reliance. It is clear that these practices are very beneficial to the development of children's creativity.

\section{Overview}

Summarizing, research consistently shows that authoritative parents tend to promote a healthy and prosocial development of their children. According to previous research, individuals who rated their parents higher in authoritative parenting will show higher peace attitudes scores (Canegallo et al., 2020). We believe that parenting can also be associated with creativity, and, at present, no one has studied the relationship between the two. So, there is a need for further study. More specifically, we expect that individuals who rated their parents higher in democratic parenting will show higher creativity scores. Creative ability prefers to engage in unique thinking because of an intrinsic desire to find new and better things. In recent years, most universities have paid much attention to cultivating students' creative ability (Zheng \& Yang, 2011). The students who possessed high creative ability can build up the ability to analyze and resolve the problems. These abilities can help foster a base for the future actual work or career.

In light of this issue, this research is undertaken to determine the undergraduate students' creativity in Zhejiang Gongshang University, China. Zhejiang Province is one of the provinces with better economic development in China. People's ideas are more open and diversified. As a key university in Zhejiang Province, taking samples from undergraduates can be more objective and reduce experimental errors. In addition, this study is conducted to identify the factors that influence their creativity. This research will examine the relationship between parenting style and creativity.

\section{Methods}

\subsection{Participants}

The sample consists of 239 undergraduate students (127 females and 112 males) between 19 and 21 years $($ mean $=20.04$ and standard deviation $=0.94)$. Participants administered a self-administered questionnaire online that stated the purpose of the research. They answered questions regarding age, majors, gender and so on. All participants spoke Chinese as their first language and were recruited from Zhejiang Gongshang University. Some of them served as a leader in student union $(20 \%, \mathrm{n}=47)$. They studied in various fields, including business, art, computer science, information technology, finance, economics, and so on.

\subsection{Creative Ability}

Previous study measured creativity by individual perceptions of opportunities to engage in creative behaviors using five items developed (Houghton \& DiLiello, 
2010). Such as, I have opportunities to use my creative skills and abilities at work. Rebecca and Magdalena (2012) argued the conceptions of creativity were five dimensions, novelty, product, problem solving, cognitive processes and personal attributes. But in this study, it was measured by the following creative ability test with several questions. One of the questions is: please draw a meaningful picture using two lines, two triangles and two circles. We considered every subject can do it no matter what his major is. Drawing a meaningful picture can get 10 points, no more than 100 scores. Other questions like how long a bird on the moon can fly a KM if it can fly 50 meters in a minute on the earth.

\subsection{Parental Styles Questionnaire}

The PSQ (Gong, 2006) is designed to measure undergraduate students' parenting styles. The questionnaire asks participants to "think about each statement as it applies to you and your mother during your years growing up at home." It comes in two nearly identical forms, differing only in terms of the mentioned parent: mother or grander mother. Before administering it, we asked participants to indicate the parent who mostly took care of them. Subsequently, we asked them to fill the corresponding version. The PSQ has four subscales: authoritarian, democratic, indulgent and neglecting styles.

Participants are asked to respond on a five-point Likert-type scale ranging from 1 ("strongly disagree") to 5 ("strongly agree"). Cronbach's alpha of PSQ ranges from 0.74 to 0.87 and test-retest reliability ranges from 0.77 to 0.87 .

\subsection{Data Analysis}

IBM SPSS 24.0 was used for all statistics procedures. In the correlation analysis, variables were creativity and PSQ's subscales. In the regression analysis, we set the creativity total score as dependent variable and the PSQ's subscales scores as independent variables: authoritarian, democratic, indulgence and neglecting styles.

\section{Result}

Descriptive statistics concerning creativity resulted as follows: 76.39 (18.12); Concerning the PSQ, 73\% of participants indicated that it was their mother who mostly took care of them while growing up and 9 of them declared that they came from a single parent family. Observed means and standard deviation values resulted as follows: Democratic parenting style, 3.06, (0.52); authoritarian, 3.31, (0.72); indulgence, 3.20, (0.56); neglecting parenting style, 3.04, (0.42).

Pearson correlation coefficients were extracted. We observed a significant positive correlation between democratic parenting style and total creativity scores $(\mathrm{r}=0.294, p<0.001)$, a significant negative correlation between authoritarian parenting style and total creativity scores $(\mathrm{r}=-0.164, p<0.001)$, and a significant negative correlation between neglecting parenting style and total creativity scores $(r=-0.154, p<0.001)$. Pearsons correlations among the study variables are presented in Table 1. 
Table 2 shows the stepwise multiple regression analysis. The independent variables included in the analysis were the four parenting styles. According to the results of the regression analysis, democratic parenting style $(\mathrm{t}=2.49, \beta=0.146$, $p=0.015)$, authoritarian parenting style $(\mathrm{t}=-4.094, \beta=-0.243, p<0.0001)$ and neglect parenting style $(\mathrm{t}=-0.644, \beta=-0.138, p<0.0001)$ can predict creativity. More specifically, higher levels of democratic parenting predict higher creativity scores. On the other hand, higher levels of authoritarian parenting predict lower creativity scores. Also, higher levels of neglecting parenting predict lower creativity scores.

\section{Discussion}

To our knowledge, our study is the first one investigating the relationship between parenting styles and creativity. There has been more attention paid to the creativity in the last 10 years than during the previous many years, in this science and technology age, teaching and enhancing the undergraduate students' most valuable creativity is a major problem which universities face to. How to teach entrepreneurial behaviour and support students to develop abilities and skills enabling them to perform entrepreneurial tasks is a key issue in entrepreneurship education (Colette et al., 2005). In this respect, creativity is important in entrepreneurship education (Hamidi et al., 2008; Lin \& Nabergoj, 2014). In efforts to develop and stimulate creativity and creative problem-solving skills,

Table 1. Correlation matrix of variables $(\mathrm{N}=239)$.

\begin{tabular}{cccccc}
\hline Variable & democratic & authoritarian & indulgence & neglecting & creativity \\
\hline democratic & 1 & 0.294 & 0.126 & 0.136 & $0.294^{* *}$ \\
authoritarian & 1 & 0.095 & 0.135 & $-0.164^{* *}$ \\
indulgence & & 1 & 0.145 & 0.054 \\
neglecting & & 1 & $-0.154^{* *}$ \\
creativity & & & & 1 \\
\hline
\end{tabular}

Notes: ${ }^{*}$ Correlation is significant at the 0.01 level (2-tailed).

Table 2. Results of stepwise multiple regression to predict creativity $(\mathrm{N}=239)$.

\begin{tabular}{ccccccccc}
\hline $\begin{array}{c}\text { Criterion } \\
\text { Variable }\end{array}$ & $\begin{array}{c}\text { Predict } \\
\text { variable }\end{array}$ & $\beta$ & Beta & T & $\begin{array}{c}\text { adjusted } \\
\text { R2 }\end{array}$ & S.E. & p-value & $\begin{array}{c}\text { Variance } \\
\text { Inflation } \\
\text { Factor }\end{array}$ \\
\hline & Democratic & 0.32 & 0.146 & 2.49 & 0.092 & 0.131 & 0.015 & 1.024 \\
$\begin{array}{c}\text { Creativity } \\
\text { scores }\end{array}$ & Authoritarian & -0.58 & -0.243 & -4.094 & & 0.142 & 0 & 1.03 \\
& Indulgence & 0.48 & 0.143 & 3.094 & & 0.122 & 0 & 1.01 \\
& Neglecting & -0.107 & -0.038 & -0.644 & & 0.166 & 0 & 1.02 \\
\hline
\end{tabular}


educators emphasise practice-based learning. A full display of creativity is indispensable, not only for developing new products and technology, but also for managing any business, even any career. In a word, those undergraduate students with higher creativity will be more easily to gain career success and subjective well-being in the future, which is helpful to individuals but also to organizations because employees' career success can eventually contribute to organizational performance. So, it is widely acknowledged that it is not only the responsibility of the university but also the responsibility of the organizations to promote individual creativity.

The results showed that there was a positive correlation between the democratic parenting style and the creativity of undergraduate students, and there was a significant negative correlation between the neglecting, authoritarian parenting style and the creativity score. Further regression analysis showed that the parenting styles of undergraduate students had some predictive effect on their creativity.

In social life, individuals follow the tradition of the previous generation, and combine their own reality of life experience gradually formed a certain, parenting concept. The concept of upbringing guides and governs the concrete, varied parenting of their daily lives. The repetition of one or more parenting behaviors forms a relatively stable parenting style which is formed and developed during the interaction between parents and children. The results of this interaction are not only reflected in the physical parenting activities of parents and children. Also from the parents to the children's behavior, the transfer of norms embodied. Parenting styles have a wide range of effects on their children, and some studies even suggest that nurturing mothers are more aware of advertising aimed at children and talk more to children regarding advertising and consumption than authoritarian mothers. Mothers who are nurturing and not authoritarian are more likely to yield to requests and favor more regulation than other parents (Wisenblit et al., 2013). Individuals who are reared with warmth (Baumrind, 1991), defined as a parenting attitude, characterized by responsiveness, intentional support of children's individuality and self-regulation, tend to have better emotion regulation skills and ability to reach and maintain emotional closeness (Eisenberg, Cumberland, \& Spinrad, 1998; Eisenberg, Spinrad, \& Cumberland, 1998; Strayer \& Roberts, 2004; Bugental \& Grusec, 2006; Morris et al., 2007). Parents who functionally use behavioral control (Baumrind, 1991) that is the practice of reliably and appropriately providing awards (attention and praise) and punishments (removal of privileges) will promote positive development and better self-control (Barber, 1996; McDowell et al., 2002; Barber et al., 2005; Moilanen, 2007). Similar to their findings, our study also found that parenting style has a strong influence on children.

Children not only need more information about the world, they also need to understand cause and effect, surface and hidden principles, in order to understand the world from a deeper, broader perspective, and to develop creativity, 
It's clear that how parents deal with their children's questions when they ask why has a different impact on fostering creativity.

Democratic, authoritarian, indulgence and neglecting styles have different characteristics. Democratic parenting are both demanding and responsive to children, with the child's physical and mental development as the center, to the child supervision but not too limited, to give guidance and help, do the child's request appropriate response, believe in the child, respect the child's will, parent-child equal communication, listen and absorb your child's perspective and encourage child to think by himself. Democratic parenting respects the nature of the child, and in the course of the child's development, the character of the parent's affirmation, respect, and encouragement is very beneficial to the child's creativity development.

Authoritarian parenting style is that the children have no or little response to the demands, and the parent is the center, excessive power and control, setting absolute standards, demanding children only according to their parents' wishes, lack of trust and understanding between parents and children, little belief that children have no warmth and two-way communication, and more use of control, refusing to communicate with children on an equal footing, striving to uphold the authority of parents, demanding obedience and respect for authority and tradition. Authoritarian parents are likely to give their children little opportunity to make mistakes, and little opportunity and space to create, so this parenting style is not conducive to creativity.

The specific characteristics of neglecting styles are neither, no demand nor response, do not ask, laissez-faire, the child does not require, do not participate in the child's activities, do not care about the physical and mental development of children. No supervision, no guidance, no control over the child's behavior. The development of children's creativity, parental guidance and inspiration is also very critical, if parents do not provide various information and opportunities, the development of children's creativity will indeed be very difficult.

Ward (2004) emphasised that creative (entrepreneurial) failures are often due to limited and constrained thinking. He further highlights the ability to combine separate and opposing ideas to move beyond established knowledge towards divergent thinking and creative thinking, similar to the concept of bisociation. Though being aware that creative thinking cannot be reduced to prosocial behaviors and that the two constructs are not in any way interchangeable, they are related and therefore constituted our starting point for this work. Literature investigating creative thinking, in fact, identifies certain personal characteristics that may be at the root of creative thinking (Strayer \& Roberts, 2004; Karmakar, 2017; Eisenberg \& Valiente, 2002).

\section{Conclusion}

In conclusion, the present study is the first one investigating the relationship between parenting styles and creativity. Results indicate that creativity correlates 
positively with democratic parenting scores, negatively with authoritarian and parenting scores, and negatively with neglecting parenting scores. This work opens the way to future research aiming at clarifying the nature of this relationship using more comprehensive measures of parenting styles and diverse samples.

According to the experimental results, we can conclude that democratic parenting can make children have a higher level of creativity. In the practice of social life, we can conclude that the government and experts should pay more attention to family education, encourage and publicize democratic education and respect children's ideas, and take certain measures to ensure children's rights and interests in family education.

\section{Limitations and Future Research Suggestions}

Although this research adds to the literature on the relationship between predictors and undergraduate students' creativity, like all research, several limitations exist that should be addressed in future research. First, this study was limited by the set of factors that were proposed to be linked to creativity. There are many predictors that have been examined in previous models of creativity, the study just proposed the impact of parenting style on creativity. However, as found in other studies creativity is sometimes affected by other variables, such as, entrepreneurship education programme. While this current study did not examine the relationship between education program and creativity. So, future studies should capture their influence.

Secondly, future research can provide additional information and extensions to these results. For example, more information is needed on the mechanisms through which parenting style translates into creativity.

Finally, our study was conducted in a single university, just recruited participants of children, future research may recruit both the actual parents of participants to collect more accurate data on parenting practices or use observational methods.

\section{Conflicts of Interest}

The authors declare no conflicts of interest regarding the publication of this paper.

\section{References}

Baker, D. F., \& Baker, S. J. (2012). To Catch the Sparkling Glow: A Canvas for Creativity in the Management Classroom. Academy of Management Learning \& Education, 11, 704-721. https://doi.org/10.5465/amle.2010.0003

Barber, B. K. (1996). Parental Psychological Control: Revisiting a Neglected Construct. Child Development, 67, 3296-3319. https://doi.org/10.2307/1131780

Barber, B. K., \& Olsen, J. A. (1997). Socialization in Context: Connection, Regulation, and Autonomy in the Family, School, and Neighborhood, and with Peers. Journal of Adolescent Research, 12, 287-315. https://doi.org/10.1177/0743554897122008 
Barber, B. K., Stolz, H. E., \& Olsen, J. A. (2005). Parental Support, Psychological Control, and Behavioral Control: Assessing Relevance across Time, Culture, and Method. Monographs of the Society for Research in Child Development, 70, 1-137.

Baumrind, D. (1968). Authoritarian vs. Authoritative Parental Control. Adolescence, 3, 255-272.

Baumrind, D. (1991). The Influence of Parenting Style on Adolescent Competence and Substance Use. The Journal of Early Adolescence, 11, 56-95. https://doi.org/10.1177/0272431691111004

Bourgeois-Bougrine, S., Buisine, S., Vandendriessche, C., Glaveanu, V., \& Lubart, T. (2017). Engineering Students' Use of Creativity and Development Tools in Conceptual Product Design: What, When and How? Thinking Skills and Creativity, 24, 104-117. https://doi.org/10.1016/j.tsc.2017.02.016

Bowlby, J. (1977). The Making and Breaking of Affectional Bonds: I. Aetiology and Psychopathology in the Light of Attachment Theory. The British Journal of Psychiatry, 130, 201-210. https://doi.org/10.1192/bjp.130.3.201

Bugental, D. B., \& Grusec, J. (2006). Socialization Theory. In K. H. Rubin (Ed.), Handbook of Child Psychology: Vol. 3. Social, Emotional, and Personality Development (pp. 366-428). New York: Wiley.

Buri, J. R. (1991). Parental Authority Questionnaire. Journal of Personality Assessment, 57, 110-119. https://doi.org/10.1207/s15327752jpa5701 13

Canegallo, V., Broccoli, E., Cavarra, M., Santoddì, E., \& Fabio, R. A. (2020). The Relationship between Parenting Styles and Peace Attitudes. Journal of Aggression Conflict and Peace Research, 12, 185-195. https://doi.org/10.1108/JACPR-04-2020-0493

Carlson, L., Grossbart, S., \& Stuenkel, J. K. (1992). The Role of Parental Socialization Types on Differential Family Communication Patterns Regarding Consumption. Journal of Consumer Psychology, 1, 31-52. https://doi.org/10.1016/S1057-7408(08)80044-7

Carlson, L., Laczniak, R., \& Walsh, A. (2001). Socializing Children about Television: An Intergenerational Study. Journal of Academy of Marketing Science, 29, 276-288. https://doi.org/10.1007/BF02890785

Colette, H., Hill, F., \& Leitch, C. (2005). Entrepreneurship Education and Training: Can Entrepreneurship Be Taught? Education + Training, 47, 98-111.

https://doi.org/10.1108/00400910510586524

Davis, A. N., \& Carlo, G. (2018). The Roles of Parenting Practices, Sociocognitive/Emotive Traits, and Prosocial Behaviors in Low-Income Adolescents. Journal of Adolescence, 62, 140-150. https://doi.org/10.1016/j.adolescence.2017.11.011

Eisenberg, N., \& Valiente, C. (2002). Parenting and Children's Prosocial and Moral Development. In M. H. Bornstein (Ed.), Handbook of Parenting: Practical Issues in Parenting (pp. 111-142, Vol. 5). Mahwah, NJ: Lawrence Erlbaum Associates Publishers.

Eisenberg, N., Cumberland, A., \& Spinrad, T. L. (1998). Parental Socialization of Emotion. Psychological Inquiry, 9, 241-273. https://doi.org/10.1207/s15327965pli0904 1

Eisenberg, N., Spinrad, T. L., \& Cumberland, A. (1998). The Socialization of Emotion: Reply to Commentaries. Psychological Inquiry, 9, 317-333. https://doi.org/10.1207/s15327965pli0904 17

Gafor, A. (2014). Construction and Validation of Scale of Parenting Style. Online Submission, 2, 315-323.

Gong, Y. H. (2006). Influence of Four Types of Parenting Styles on Achievement Motivation Levels of Individuals. Chinese Journal of Clinical Rehabilitation, 10, 50-52.

Guilford, J. P. (1950). Creativity. American Psychologist, 5, 444-454. 
https://doi.org/10.1037/h0063487

Gurteen, D. (1998). Knowledge, Creativity and Innovation. Journal of Knowledge Management, 2, 5-13. https://doi.org/10.1108/13673279810800744

Hamidi, D. Y., Wennberg, K., \& Berglund, H. (2008). Creativity in Entrepreneurship Education. Journal of Small Business and Enterprise Development, 15, 304-320. https://doi.org/10.1108/14626000810871691

Houghton, J. D., \& Di Liello, T. C. (2010). Leadership Development: The Key to Unlocking Individual Creativity in Organizations. Leadership \& Organization Development Journal, 31, 230-245. https://doi.org/10.1108/01437731011039343

Karmakar, R. (2017). The Impact of Perception of Consistency and Inconsistency in Parenting Style on Pro-Social Motives of Adolescents. Social Psychology and Society, 8, 101-115. https://doi.org/10.17759/sps.2017080207

Lin, J., \& Nabergoj, A. S. (2014). A Resource-Based View of Entrepreneurial Creativity and Its Implications to Entrepreneurship Education. Economic and Business Review, 16, 163-183.

McDowell, D. J. et al. (2002). Children's Emotional Regulation and Social Competence in Middle Childhood: The Role of Maternal and Paternal Interactive Style. Marriage \& Family Review, 34, 345-364. https://doi.org/10.1300/J002v34n03 07

Moilanen, K. L. (2007). The Adolescent Self-Regulatory Inventory: The Development and Validation of a Questionnaire of Short-Term and Long-Term Self-Regulation. Journal of Youth and Adolescence, 36, 835-848. https://doi.org/10.1007/s10964-006-9107-9

Morris, A. S. et al. (2007). The Role of the Family Context in the Development of Emotion Regulation. Social Development, 16, 361-388. https://doi.org/10.1111/j.1467-9507.2007.00389.x

Neeley, S., \& Coffey, T. (2007). Understanding the "Four-Eyed Four-Legged" Consumer: A Segmentation Analysis of US Moms. Journal of Marketing Theory and Practice, 15, 251-261. https://doi.org/10.2753/MTP1069-6679150305

Prinzie, P. et al. (2009). The Relations between Parents' Big Five Personality Factors and Parenting: A Meta-Analytic Review. Journal of Personality and Social Psychology, 97, 351-362. https://doi.org/10.1037/a0015823

Rebecca, H. P. C., \& Magdalena, M. C. M. (2012). A Study of Early Childhood Teachers' Conceptions of Creativity in Hong Kong. Educational Psychology: An International Journal of Experimental Educational Psychology, 33, 119-133. https://doi.org/10.1080/01443410.2012.735645

Shalley, C. E. (1991). Effects of Productivity Goals, Creativity Goals and Personal Discretion on Individual Creativity. Journal of Applied Psychology, 76, 179-185. https://doi.org/10.1037/0021-9010.76.2.179

Strayer, J., \& Roberts, W. (2004). Children's Anger, Emotional Expressiveness, and Empathy: Relations with Parents' Empathy, Emotional Expressiveness, and Parenting Practices. Social Development, 13, 229-254. https://doi.org/10.1111/j.1467-9507.2004.000265.x

Tanner, D. (1992). Applying Creative Thinking Techniques to Everyday Problems. The Journal of Consumer Marketing, 9, 23-26. https://doi.org/10.1108/07363769210037051

Ward, T. B. (2004). Cognition, Creativity, and Entrepreneurship. Journal of Business Venturing, 19, 173-188. https://doi.org/10.1016/S0883-9026(03)00005-3

Wisenblit, J. Z., Priluck, R., \& Pirog, S. F. (2013). The Influence of Parental Styles on Children's Consumption. Journal of Consumer Marketing, 30, 320-327.

https://doi.org/10.1108/JCM-02-2013-0465 
Zheng, L., \& Yang, L. (2011). Entrepreneurship Education and Employment Performance: An Empirical Study in Chinese University, Entrepreneurship Education. Journal of Chinese Entrepreneurship, 3, 195-203.

https://doi.org/10.1108/17561391111166975 